\title{
Does Purchasing Power Parity hold? New evidence from wild-bootstrapped nonlinear unit root tests in the presence of heteroskedasticity
}

\author{
Jen-Je Su ${ }^{a}$, Adrian (Wai-Kong) Cheung ${ }^{b}$ and Eduardo Roca ${ }^{a}$ \\ ${ }^{a}$ Department of Accounting, Finance and Economics, Griffith University, Nathan, \\ Queensland, 4111, Australia \\ ${ }^{b}$ Department of Finance and Banking, School of Economics and Finance, Curtin \\ University, Bentley, Western Australia 6102, Australia
}

\begin{abstract}
In spite of the extensive research which has already been undertaken, the issue as to whether Purchasing Power Parity (PPP) empirically holds, continues to be strongly debated. Existing studies have been criticised for their reliance on unit root tests which are deemed to suffer from certain weaknesses such as the size distortion bias arising from heteroskedasticity. In this paper, we provide new evidence on PPP based on a new methodology that overcomes this problem. We use the widely accepted KSS (Kapetanios, Snell, and Shin (2003)) non-linear unit root tests which we, however, wild bootstrapped. Through Monte Carlo simulation, we demonstrate that the wild-bootstrapped KSS is robust to heteroskedasticity-induced size distortion problem. We apply this method to test PPP across 61 countries over the period 1994 to 2012 - a period characterised by a number of crises such as the Asian Financial Crisis, Russian Crisis, dotcom crisis, Global Financial Crises, among others, and therefore, intense heteroskedasticity. Our results provide strong evidence against PPP. This paper contributes to both the international financial economics and econometrics literatures.
\end{abstract}

Keywords: (nonlinear) unit root test, heteroskedasticity, wild bootstrapping, purchasing power parity JEL Classification Codes: C10, C12, C22, C50 


\section{[1] Introduction}

Purchasing Power Parity (PPP), as first articulated by Cassel $(1918,1922)$, is one of the key assumptions in open macroeconomics and international finance models; however, after thirty years of intensive research, the empirical validity of PPP remains far from conclusive. PPP is a simple idea based on the law of one price which postulates that identical goods should sell at the same price in different countries and that the exchange rates between currencies will allow this to happen. In the absolute version of the PPP, the exchange rate would simply be the ratio of the price levels between countries. On the other hand, in the relative version of the PPP, the change in exchange rates offsets the differential in the relative change in prices between countries which implies that the real exchange rate (RER) will be stationary (see Taylor, 2006 and Sarnoff and Taylor, 2002 and Taylor and Taylor, 2004 for a detailed discussion of PPP). Hence, the PPP hypothesis is typically examined by testing if RERs are stationary using unit root tests. Earlier studies, which were often based on the Dickey-Fuller (DF) tests, found little evidence to support PPP (e.g. Adler and Lehmann (1983)). The failure has been attributed to the low power of the DF tests and the literature has consequently moved on to enhance the testing power using various approaches (see, for example, Rogoff (1996) and Taylor and Taylor (2004)).

One of the new developments in the PPP empirics is the use of nonlinear unit root tests. Due to the existence of transactions costs, according to Michael et al (1997) and Taylor et al (2001), RERs may revert to the long-run equilibrium only when they are sufficiently distant from the long-run equilibrium; in other words, RERs are globally stationary but adjusted in a nonlinear (threshold-like) fashion. The DF-type tests, which are 
developed in a linear (autoregressive) context, may exhibit low power against such nonlinear stationarity. To address the problem, a range of nonlinear unit-root tests have been suggested - see, for example, Enders and Granger (1998), Kapetanios et al. (2003) (hereafter, KSS), Bec et al. (2004), Sollis (2009). Among these, KSS (2003) is probably the most widely recognized and applied. KSS (2003) proposed a unit-root test using an auxiliary regression model that approximates the exponential smooth transition autoregressive (ESTAR) process by Taylor series. Using the KSS test, stronger supporting evidence of PPP has been found - see, among others, KSS (2003), Liew et al. (2004), Bahmani-Oskooee et al. (2007), Pesaran et al. (2009), Zhou and Kutan (2011).

Unit root tests may suffer non-trivial size distortion in the presence of conditional heteroskedasticity (e.g. generalized autoregressive heteroskedasticity (GARCH)) as well as unconditional time-varying variance (non-stationary volatility). As shown in Valkanov (2005), with strong $\mathrm{GARCH}$ effect (i.e. when the $\mathrm{GARCH}$ process is nearly integrated and the volatility parameter is relatively large) often observed in economic/financial time series, convergence of the finite-sample DF distribution to the asymptotic distribution appears to be very slow. As a result, the usual DF test tends to be oversized in the presence of strong GARCH effect (see also Kim and Schmidt (1993) and Su (2011)). Cook (2006) also found that the size distortion due to GARCH can be even more severe when the (nonlinear) KSS test is considered. In addition, many economic and financial variables (including foreign exchange rates) are characterized by the existence of permanent volatility breaks (see, for example, Loretan and Phillips (1994) and Busetti and Taylor (2003)). In theory, permanent shifts in volatility can greatly affect linear unit root inference not only in finite samples but also asymptotically (Hamori and Tokihisa (1997), Kim et al. (2002) and Cavaliere (2004)). 
However, the impact of volatility shifts to nonlinear unit root tests remains largely unexplored.

We propose to use the wild bootstrap method to overcome the aforementioned size problems. The idea behind this method is to replicate in resampled data the pattern of heteroskedasticity in the original data. As shown in Cavaliere and Taylor $(2008,2009)$ the wild bootstrap inference is robust to both conditional and unconditional heteroskedasticity and is able to achieve the (infeasible) size-corrected power of the usual (linear) unit root tests. Interestingly, even though the statistical performance of wild-bootstrapping has not yet been examined in the literature for the nonlinear unit root tests, there are two empirical works that have already incorporated the wild bootstrap method to the KSS test (Arghyrou and Gregoriou $(2007,2008))$. Both papers found apparently conflicting results between the standard and bootstrapping inferences. On one hand, Arghyrou and Gregoriou (2007) found that the standard and bootstrap approaches arrive in the same conclusion when the DF test is considered: none of the 7 bilateral RERs (against the US dollar) they examined is stationary. On the other hand, Arghyrou and Gregoriou (2008) reported that nonstationarity is rejected in 6 out of the 7 RERs when the standard KSS inference is applied but, strikingly, only 1 rejection with the associated wild bootstrap inference. ${ }^{1}$ Given the findings of Arghyrou and Gregoriou (2007, 2008), one might doubt if the results that are biased toward PPP from the KSS test is nothing but a product of size distortion owing to heteroskedasticity. Once heteroskedasticity is appropriately accounted for, can KSS test still produce more support for PPP than DF?

\footnotetext{
${ }^{1}$ We note that Arghyrou and Gregoriou (2008) do not deal with GARCH or time-varying volatility; instead, the wild bootstrap method is used to account for non-normality.
} 
In this paper, we aim to shed lights on these issues. First, we show that the KSS test is more size-distorted than the DF test in the presence of non-constant variances. Second, we show that the wild bootstrap method that works well with the DF test also works satisfactorily with the KSS test. Third, we apply the DF and KSS tests to 61 real effective exchange rates (REERs) with data from the Bank of International Settlement (BIS). We find that wild bootstrap implementation of the KSS test produces much less rejection of nonstationarity than standard implementation but the KSS test still rejects more often than the DF test, suggesting that the real exchange rates are non-stationary in most of these countries. This finding also implies that the PPP does not hold and arbitrage opportunities exist. Possible economic explanations include transaction costs (Dumas, 1992; Sercu, Uppal and Van Hulle, 1995; Obstfeld and Taylor, 1997), limits to arbitrage (Zussman, 2002), heterogeneous agents (Reitz and Taylor, 2008), presence of target zones (Krugman, 1991), central bank interventions (Dominguez, 1998; Lee, 2011).

Our paper contributes to both the international financial economics and the econometrics literatures. In terms of its contributions to the international financial economics literature, our paper provides fresh evidence on PPP - an issue that is still highly debated notwithstanding the large body of research on this topic which has built up since the early 1970s. It has been suggested that in order to move this debate forward constructively, there is a need for empirical studies which incorporate non-linearities, as first pointed out by Rogoff (1996) and use data sets with more extensive coverage (Sarno and Taylor, 2002; Taylor and Taylor, 2004; Taylor, 2006). Our study fills these important gaps in the literature. As mentioned, our paper examines an extensive number of countries - 61 in total, and is based on a more updated data set over a period of 18 years (1994-2012) 
that is characterised by the occurrence of a number of financial crises and therefore, of high heteroskedasticity.

In relation to our paper's contribution to the econometrics literature, through Monte Carlo simulation, we demonstrate that wild bootstrapping the KSS test eliminates the size distortion problem induced by heteroskedasticity. This has not been done previously in the literature. Arghyrou and Gregoriou (2008) incorporated wild bootstapping into KSS test but they did not conduct any simulation to prove that the KSS test works well with wild bootstrapping. The statistical properties of wild bootstrapping has been examined in the literature but this is only in relation to linear unit root tests such as the DF tests (see, for example, Cavaliere and Taylor $(2008,2009))$.

The rest of the paper proceeds as follows. Section 2 discusses the Monte Carlo simulation setups and presents results from the simulations. Section 3 reports the empirical results and Section 4 concludes. A brief review of the unit root tests and wild bootstrapping procedure can be found in Appendix A.

\section{[2] Monte Carlo Simulation Setup and Results}

\section{Setup for size issue and results}

To investigate the size properties of the DF and KSS tests. The data-generating process is a drift-less integrated process $y_{t}=y_{t-1}+\varepsilon_{t}, \mathrm{t}=1, \ldots, \mathrm{T}$, with heteroskedastic errors: 
$\varepsilon_{t}=\omega_{t} \sigma_{t}$ where $\sigma_{t}$ is iid $\mathrm{N}(0,1)$ and the volatility parameter $\omega_{t}$ is specified as the following models.

1. No break: $\omega_{t}=1$.

2. GARCH: $\omega_{t}=\phi_{0}+\phi_{1} \varepsilon_{t-1}^{2}+\phi_{2} \omega_{t-1}$.

3. (Exponential (Near-)Integrated) Stochastic volatility (SV): $\omega_{t}=\omega_{0} \exp \left(b \xi_{t} / \sqrt{T}\right)$ where $\xi_{t}=(1-c / T) \xi_{t-1}+k_{t}$, with $k_{t} \sim$ iid $\mathrm{N}(0,1)$.

4. Single break (SB) in volatility: $\omega_{t}=\omega_{0}+\left(\omega_{1}-\omega_{0}\right) \mathrm{I}\left(\frac{t}{T} \geq \tau\right), \tau \in(0,1)$.

5. Double break (DB) in volatility: $\omega_{t}=\omega_{0}+\left(\omega_{1}-\omega_{0}\right) \mathrm{I}\left(\tau_{1} \leq \frac{t}{T} \leq \tau_{2}\right), \tau_{1}, \tau_{2} \in(0,1)$.

6. Trending Volatility (TV): $\omega_{t}=\omega_{0}+\left(\omega_{1}-\omega_{0}\right)\left(\frac{t-1}{T-1}\right)$

Model 2 is the standard $\operatorname{GARCH}(1,1)$ model the parameters of which are set as follows: $\left(\phi_{1}, \phi_{2}\right)=(0.29,0.7),(0.2,0.7),(0.19,0.8),(0.1,0.8)$ and $\phi_{0}=1-\phi_{1}-\phi_{2}$. The SV process of Model 3 is generated with $b=2$ and $c=0,10$. Models 4-6 refer to those nonstationary volatility cases considered in Cavaliere and Taylor $(2008,2009)$. Note that the variance of $\varepsilon_{t}$ is $\operatorname{var}\left(\varepsilon_{t}\right)=\omega_{t}^{2}$. Model 4 corresponds to a single abrupt variance shift from $\omega_{0}^{2}$ to $\omega_{1}^{2}$ occurring at $\mathrm{t}=\tau T$. Model 5 is with double shifts: the first shift at $\mathrm{t}=\tau_{1} T$ (from $\omega_{0}^{2}$ to $\omega_{1}^{2}$ ) and the second shift at $\mathrm{t}=\tau_{2} T$ (from $\omega_{1}^{2}$ to $\omega_{0}^{2}$ ). Model 6 generates smooth (trending) breaks over the whole sample period $t=1$ to $T$. For these three models, we let $\omega_{0}=1$ and set $\delta\left(=\omega_{0}^{2} / \omega_{1}^{2}\right)$ equal to $1 / 2,2,1 / 5,5$, respectively. We note that $\delta<1$ 
corresponds to a downward shift while $\delta>1$ upward shift. For Model 4 (SB): we consider $\tau$ $=0.2$ (early break), 0.8 (late break). For Model 5 (DB), we set $\tau_{2}=\left(1-\tau_{1}\right)$ and $\tau_{1}=0.2,0.8$.

All simulations are based on 20,000 replications with $T=100,250$ and done by GAUSS. For the wild bootstrapping, we use the warp-speed Monte Carlo method of Giacomini et al. (2013) using a single bootstrap re-resample (i.e. $M=1$ in Step 3 of the bootstrap procedure described in Appendix A) and the bootstrap critical values are obtained based on the 20,000 Monte Carlo replications. Rejection frequencies are calculated at the $5 \%$ nominal significance level with the DF and KSS tests using the standard and bootstrap inferences, respectively. For simplicity, in both tests we set the augmentation equal to zero. ${ }^{2}$ We report the simulation results in Table 1 and the results can be summarized as follows. First, in the absence of variance break all tests are correct-sized. Second, both standard (DF and KSS) tests over-reject the null hypothesis in the presence GARCH errors and the scale of over-rejection is larger as the sample size increases. Also, consistent with the findings of Cook (2006), the KSS test tends to over-reject significantly more often than the DF test. ${ }^{3}$ In contrast, the size of the wild-bootstrapped tests (DF-WB and KSS-WB) is about right. Third, in the SV models, both the DF and KSS tests are oversized and the KSS test is far worse than the DF test. On the contrary, the bootstrap tests are about correct-sized. Fourth, with a single abrupt variance break (SB), standard tests are oversized with downward variance shifts and, in line with Cavaliere and Taylor (2007, 2008), the oversizing problem is more severe in the Level case (Case A) for early $(\tau=0.2$ ) and strong contraction ( $\delta=1 / 5)$. In the case of an upward variance shift, both DF and KSS tests can be over-sized or under-sized. Again, the bootstrap tests are about correct-sized. Fifth, the size properties for both DF and

\footnotetext{
${ }^{2}$ We have also considered augmented tests and, as expected, the results are very similar.

${ }^{3}$ As Cook (2006), we have also considered tests with the White standard error. But we find that the bootstrap tests outperform the White tests in terms of size and power.
} 
KSS tests in DB and TV models are similar to those with SB. However, the magnitude of size distortion is relatively moderate comparing with SB. Again, the rejection rate for the DF-WB and KSS-WB tests are close to the $5 \%$ nominal rate regardless of whether or not the variance shift is downward or upward, early or late, and with abrupt or smooth breaks.

Overall, our simulation results show that the standard KSS test tends to be more vulnerable to size distortion than the DF test in models with conditional and unconditional heteroskedasticity. When it comes to controlling size, the wild bootstrap method not only works well for DF test but also for the KSS test too.

\section{Setup for power issue and results}

We now turn to the power of the wild bootstrap tests. Simulations are performed for two sets of experiments: a stationary $A R(1)$ process:

$$
y_{t}=\rho y_{t-1}+\varepsilon_{t}
$$

and a statioanry ESTAR process:

$$
y_{t}=y_{t-1}+\gamma y_{t-1}\left\{1-\exp \left(-\theta y_{t-1}^{2}\right)\right\}+\varepsilon_{t} \text {. }
$$

We set $\rho=0.9$ for the AR(1) model and $\theta=0.01$ and $\gamma=-1,-0.5$ for the ESTAR model. For the error term $\varepsilon_{t}$, various models from Models 1 to 6 (as in the size case) are examined. ${ }^{4}$ Rejection frequencies are calculated at the $5 \%$ nominal significance level with the DF and KSS tests using the standard and bootstrap inferences and for the standard tests, the

\footnotetext{
${ }^{4}$ Other sets of AR and ESTAR parameters and variance break models are considered, the main results are very similar.
} 
(infeasible) size-corrected power is considered. We report the power at the $5 \%$ level in Table 2.

The key findings in Table 2 can be summarized as follows. First, as expected, the DF test is more powerful than the KSS test against stationary AR while the KSS test is in general more powerful against stationary ESTAR, regardless of the sample size, variance break, level or trend, standard or bootstrapped. Second, for both standard DF and KSS tests, the sizecorrected power varies over break models. Comparing with the no-break case, the power is lower for cases with over-sizing (e.g., GARCH[1], SV[1] and SB[1], see Table 1) but higher for cases with under-sizing (e.g., SB[3]). Third, in most cases, the bootstrap power, for both DFWB and KSS-WB tests, is either close to or even better than the corresponding (infeasible) sized-correct power of DF and KSS tests. This result confirms that the wild bootstrap method works not only for the linear DF test but also for the nonlinear KSS test as well.

\section{[3] PPP empirics}

In this section, we apply the standard and bootstrapped DF and KSS tests to the monthly real effective exchange rate (REER) compiled by the Bank for International Settlement (BIS) over the period 1994 to 2012. There are 228 monthly observations per REER. The BIS broad-weighted REER dataset contains 61 currencies worldwide using timevarying weights based on the average trade share over three-year periods, starting from 1993. The time-varying weights are used to capture the rapid change of the world trade pattern over the last two decades (particularly, for the so-called BRICS countries - Brazil, 
Russia, India, China, and South Africa). See Klau and Fung (2006) for the details of construction of the BIS REER dataset and Bahmani-Oskooee et al. (2009) for an application that examines PPP with this dataset.

To assess the behaviour of volatility in the BIS REER series, we estimate the variance profile, $\eta(s)$ in (A3), of each series by:

$$
\hat{\eta}(s)=\frac{\sum_{t=1}^{[s T]} \Delta \hat{y}_{t}^{2}+(s T-[s T]) \Delta \hat{y}_{[s T]+1}^{2}}{\sum_{t=1}^{T} \Delta \hat{y}_{t}^{2}},
$$

where $\Delta \hat{y}_{t}$ the first difference of the detrended series. Cavaliere and Taylor (2007) show that $\hat{\eta}(s)$ is a consistent estimator for $\eta(s)$. We plot $\hat{\eta}(s)$ against the $45^{\circ}$ line in Figure 1 and note that substantial deviations from the $45^{\circ}$ line signals variance shifts. Among the 61 REERs, some (e.g. France, Luxemburg and Malta) show constant variance process but many others appear to be with time-varying variances. For some series (e.g. Argentina, Indonesia and Malaysia) the shifts follows relatively abrupt transition paths, while for others (e.g. Estonia, Hungary and Italy) the path tends to be slower and consistent with smoothtransition breaks. For examples, the estimated variance profile of Estonia follows a relatively smooth arc above the $45^{\circ}$ line and is consistent with downward trending volatility - in contrast, Hungary's profile is consistent with upward trending volatility. Note that for REERs with considerable variance breaks, according the simulation result in Section 3, the standard unit root test results might be misleading due to size distortion.

To adjust for serial correlation that may exist in the data, we adopt the re-scaled modified Akaike information criterion (RSMAIC) for the selection of augmentation lags in the 
ADF regressions (i.e., $p$ in Equation (A1)). ${ }^{5,6}$ Cavaliere et al. (2013) shows that RSMAIC can avoid a tendency to over-fit the lag order under heteroskedasticity. ${ }^{7}$ RSMAIC may be calculated as

$$
\operatorname{RSMAIC}(k)=\ln \hat{\sigma}_{k}^{2}+k \frac{C_{T}+\hat{\tau}_{T}(k)}{T}
$$

where $C_{T}=2, \hat{\tau}_{T}(k)=\left(\hat{\sigma}_{k}^{2}\right)^{-1} \hat{\gamma}^{2} \sum_{p_{\max }+1}^{T}\left(\hat{y}_{t-1}^{d}\right)^{2}, \hat{\sigma}_{k}=\left(T-p_{\max }\right)^{-1} \sum_{t=p_{\max }+1}^{T}\left(\hat{\varepsilon}_{k, t}^{d}\right)^{2}$, $\hat{\gamma}$ and $\hat{\varepsilon}_{k, t}^{d}$ are the coefficient of lagged dependent variable and the OLS residual estimated from a $\mathrm{k}^{\text {th }}$ order ADF regression on $\hat{y}_{t}^{d}$, which is the OLS detrended series of $y_{t}$. Following Cavaliere et al. (2013), we set $p_{\max }=\operatorname{int}\left(12 *(t / 100)^{1 / 4}\right)$ where int(.) means taking integer part out of (.). As a further refinement, the sieve (recoloring) procedure of Chang and Park (2003) and Palm et al. (2007) is also used. The procedure is to generate a series of new residual recursively from $a k^{\text {th }}$ order moving average process using the $k$ coefficients estimated from the ADF regression and to substitute this residual and the bootstrap residuals into the partial sum process as described in Step 1 of the wild bootstrap algorithm (see Appendix A).

Table 3 reports the outcome of the (standard and bootstrap) DF and KSS tests for the 61 BIS REERs. Tables 3(a) and 3(b) show that the ADF test performs quite consistently in both asymptotic and wild bootstrap p-values. ${ }^{8}$ We cannot reject the unit root null hypothesis in most of the 61 countries. At the $10 \%$ significance level, in the constant mean cases stationarity can only be found in 5 countries (i.e., Algeria, China, Estonia, Indonesia

\footnotetext{
${ }^{5}$ Note that to focus on assessing the impact of heteroskedasticity our simulation setup assumes away the problem of serial correlation that may be commonly found in reality.

${ }^{6}$ It has been found in Su et al. (2013) that setting the number of augmented lags for the KSS regression (q) the same as that of the DF regression ( $p$ ) results in better performance. Given this finding, throughout this section, we set $q=p$.

${ }^{7}$ Other methods of augmentation lag selection are considered. While the results may vary somewhat, the key conclusion does not change.

${ }^{8}$ The asymptotic p-value in Table 3 is obtained using the simulated DF and KSS distributions while the bootstrap $p$-value is obtained using the bootstrap distributions.
} 
and Lithuania) when the asymptotic distribution is referred to and in 7 countries (i.e., Algeria, Estonia, Indonesia, Korea, Lithuania, Poland and South Africa) using the bootstrap distribution; if a linear trend is assumed to catch the Balassa-Samuelson effect, then 6 countries (i.e., Estonia, Taipei, India, Norway, Slovenia and Turkey) referring to the asymptotic distribution and 5 (i.e., Taipei, India, Norway, Slovenia and Turkey) with the bootstrap distribution are found to have stationary exchange rates. Out of the 61 REERs, there are only three (one) exceptions in the constant mean (linear trend) case where the asymptotic and bootstrap p-values provide conflicting signals. In two cases (i.e., China and Estonia) the asymptotic $p$-value indicates rejection but the wild bootstrap $p$-value says the opposite. In another two cases (i.e., Poland and South Africa), the asymptotic p-value recommends no rejection but the wild bootstrap p-value suggests the otherwise.

Turning to the KSS test, we note that the KSS test rejects the PPP hypothesis more frequently than the DF test regardless of whether the asymptotic or bootstrap distribution is referred to. We note that the wild bootstrap $p$-value depicts results different from that of the asymptotic $p$-value. Table 3(a) shows that out of the 61 countries, the asymptotic $p$ value identifies 19 stationary cases while the wild bootstrap p-value finds 9 cases only. If a linear trend is assumed, then Table 3(b) identifies 17 stationary cases with asymptotic pvalue and 11 similar cases with wild bootstrap $p$-value. In addition, there are nine and seven cases in Table 3(a) and Table 3(b), respectively, where these $p$-values provide inconsistent results - in some countries. We note that the two KSS p-values can be rather different for some countries - for example, Bulgaria, Mexico and Iceland in the constant mean case and Bulgaria, Malaysia and Venezuela in the trend case. Referring to the variance profile of these countries depicted in Figure 1, we can obviously see the variance of theses REERs is 
considerably time-varying and, based on the simulation results from the previous section the asymptotic $p$-value in these cases may result in over-rejection.

There are four cases in Table 3(a) and seven cases in Table 3(b) where the KSS-WB test cannot reject the PPP hypothesis while the ADF-WB test suggests the otherwise. This is consistent with the view that REERs are stationary with nonlinear mean reversion. Interestingly, most of these cases in the two tables happen to be the same and they are China, Romania, Switzerland and Thailand, respectively. Note that China maintains a crawling peg while Romania and Thailand both adopt a managed float system ${ }^{9}$; the former allows exchange rate to float within a narrow band that can be periodically adjusted or aligned while the latter allows governments to intervene when they think fit. The target zone model of Krugman (1991) and subsequent refinements show that a credible commitment to intervene at both edges of the band can produce a nonlinear relationship between exchange rates and fundamentals. Recently, Lee (2011) also builds an exchange rate model of managed float under conditional official intervention where the dynamics of exchange rates are also shown to be nonlinear (i.e., regime-switching). Both systems are shown to exhibit nonlinear exchange rate dynamics. Even in the case of Switzerland which was regarded by IMF as an independently floating system, the announcement by the Swiss National Bank on 6 September 2011 that it will set a minimum exchange rate of 1.20 francs to the euro, effectively says to the world that Switzerland has abandoned the clean float system and adopted a managed float system. ${ }^{10}$

\footnotetext{
${ }^{9}$ IMF (2008).

${ }^{10}$ Wille (2011).
} 
As clearly shown in Figure 1, the variance profile reveals that heteroskedasticity is quite common in the exchange rates of many countries, we focus our discussion on the results of the wild bootstrapping implementation of KSS test because it allows for heteroskedasticity. The result shows that at $10 \%$ significance level we can only reject the unit root null hypothesis for 9 countries in the constant mean case (Table 3(a)) and 11 countries in the linear trend case (Table 3(b)), respectively. In other words, after accounting for heteroskedasticity, we find strong evidence that there is a non-stationarity problem in the REERs of many countries in the sample.

Finally, it is worth noting that our empirical results corroborate the findings of Arghyrou and Gregoriou $(2007,2008)$ in testing for PPP. For the DF test, the standard and bootstrap approaches arrive at a similar conclusion. However, the standard KSS inference rejects the PPP hypothesis much more often than the associated wild bootstrap inference (due to the existence of time-varying volatility). In other words, part of the rejection arising from the standard KSS inference might be spurious because of over-sizing. We also note that Arghyrou and Gregoriou $(2007,2008)$ do not consider the Balassa-Samuelson effect which matters for many countries (e.g. Taiwan and Japan).

\section{[4] Conclusion}

We re-examine whether PPP holds given that the issue is still being highly debated due significantly to crucial shortcomings of the econometric techniques used to examine this issue in previous studies. In particular, we refer to the inference problem in unit root tests 
in the presence of conditional and unconditional heteroskedasticity. This heteroskedasticity may result in a non-trivial size distortion problem in unit root tests. In order to overcome these problems, we apply the widely used KSS non-linear unit root test but we wild bootstrapped this test. Using Monte Carlo simulation, we have confirmed that the KSS test also suffer from the size distortion problem. More importantly, the KSS test is found to be more size-distorted than the linear DF test in the presence of heteroskedasticity. However, our simulation results show that the wild bootstrap strategy works very well with both linear unit root test (i.e., ADF test) as well as nonlinear unit root test (i.e., KSS test) in controlling the size problem. We apply the wild-bootstrapped KSS test to a Bank of International Settlement dataset of monthly real effective exchange rates (REERs) for 61 countries over the period 1994 to 2012, a period which has been identified to have substantial heteroskedasticity in REERs as a result of the occurrence of a number of crises such as the Asian Financial Crisis, Russian Crisis, dot come crisis, Global Financial Crisis, among others. Our results show that most of the REERs are non-stationary. Thus, after accounting for heteroskedasticity as well as non-linearity through the use of the wildbootstrapped KSS test, we found strong evidence against the PPP hypothesis

\section{Appendix A. Wild bootstrapping unit root tests}

The basic idea behind the tests discussed in this section is to use the wild bootstrap method to control for the size distortion due to heteroskedasticity. Let $y_{t}, \mathrm{t}=1,2, \ldots, \mathrm{T}$, be an observed time series (e.g., RER) which can be decomposed into a deterministic part $d_{t}$ and a stochastic (mean-adjusted) part $v_{t}: y_{t}=d_{t}+v_{t}$. For the deterministic part, we consider 
two cases: Case A (level): $d_{t}=\alpha$; Case B (trend): $d_{t}=\alpha+\beta t$. Following the PPP literature, the level case is the baseline setting while the trend case is often referred to as the case that adjusts for "productivity bias" due to the so-called Balassa-Samuelson effect; see BahmaniOskooee and Nasir (2005) for a recent review on this matter. We first obtain the OLS residuals $\left(\hat{v}_{t}\right)$ from either case then the residuals are used for the following augmented regression models:

$$
\begin{aligned}
& \text { (DF) } \Delta \hat{v}_{t}=\gamma \hat{v}_{t-1}+\sum_{j=1}^{p} \phi_{j} \Delta \hat{v}_{t-j}+\varepsilon_{t}, \\
& \text { (KSS) } \Delta \hat{v}_{t}=\delta \hat{v}_{t-1}^{3}+\sum_{j=1}^{q} \varphi_{j} \Delta \hat{v}_{t-j}+e_{t} .
\end{aligned}
$$

The (augmented) DF and KSS tests are based on the usual t-test from the above regressions for the unit root null hypothesis $H_{0}: \gamma=0$ and $H_{0}: \delta=0$, respectively. Both DF and KSS tests are left-tailed tests. We note that the KSS regression is derived from the first-order Taylor approximation of the ESTAR model and the lag augmentations are entered in a linear fashion (KSS (2003)).

When the errors in the DF regression (A1) are heteroskedastic, the DF test is considerably size-distorted. In particular, with nonstationary volatility, Cavaliere and Taylor $(2007,2008)$ showed that linear unit root tests are no longer asymptotically pivotal as their limiting null distribution depends on a nuisance parameter: the variance profile that characterizes the time-series behaviour of the volatility. Assume that the error term in (A1): $\varepsilon_{t}=\sigma_{t} \mu_{t}$ where $\mu_{t}$ is iid $(0,1)$ and the volatility term satisfies $\sigma_{[s T]}=\omega(s)$ for all $s \in(0,1)$ with $\omega(s)>0$. The variance profile is defined as 


$$
\eta(s):=\left(\int_{0}^{1} \omega(r)^{2} d r\right)^{-1} \int_{0}^{s} \omega(r)^{2} d r
$$

The variance profile satisfies $\eta(s)=s$ when the variance is constant, while it deviates from $s$ if $\sigma_{t}$ is not constant. It is straightforward to show that if the error term in (A2) has a timevarying volatility, the usual KSS test is not asymptotically valid as its limiting null hypothesis depends on the variance profile.

Cavaliere and Taylor (2008) proposed the use of wild-bootstrapping in handling the size issue. Basically, the wild bootstrap algorithm is as follows.

[Step 1] Generate the bootstrap residuals: $\varepsilon_{t}^{b}=\hat{\varepsilon}_{t} \eta_{t}$ where $\hat{\varepsilon}_{t}$ is the ADF residuals in (A1) and $\eta_{t}$ is a random sequence with $E\left(\eta_{t}\right)=0$ and $E\left(\eta_{t}^{2}\right)=1$. Form the bootstrap sample by constructing the partial sum process $v_{t}^{b}=v_{0}^{b}+\sum_{i=1}^{t} \varepsilon_{t}^{b} \quad(\mathrm{t}=1,2, . ., \mathrm{T})$, and set the initial condition $v_{0}^{b}=0$. Note that we may generate bootstrap residuals based on the KSS regression residuals (from (A2)), the DF residuals (from (A1)), or simply the first difference of $y_{t}$ (so that both DF and KSS tests are actually based on the same bootstrap series). In our case, the (mean-adjusted) first difference is used in simulation.

[Step 2] Compute the ADF statistic based on $\left\{v_{t}^{b}\right\}_{t=1}^{T}$ and label the new statistic DF-WB.

[Step 3] Repeat Step 1 and $2 \mathrm{M}$ times to form a wild-bootstrap distribution of the DF statistic: $\{D F-W B(j)\}_{j=1}^{M}$.

Here are a few remarks on the bootstrap procedure. First, according to Cavaliere and Taylor (2008), the bootstrap residuals $\varepsilon_{t}^{b}$ do not have to be generated based on $\hat{\varepsilon}_{t}$, using the first difference of the observed data $y_{t}$ (with a mean correction in the trend case) can 
also do the job (and sometimes, even perform better in finite samples). Second, a sieve (recoloring) procedure can be added in Step 1 to achieve refinement (see Palm et al. (2008)). Third, the random sequences $\eta_{t}$ are generated based on the two-point distribution suggested in Liu (1988) and Mammen (1993)

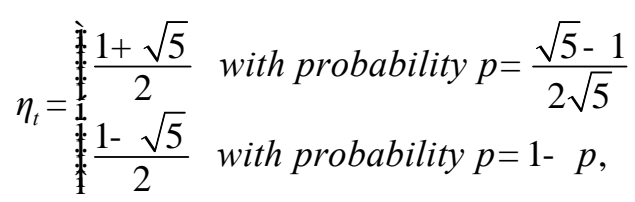

which meets the necessary requirements for wild bootstrapping (i.e. $E\left(\eta_{t}\right)=0$ and $E\left(\eta_{t}^{2}\right)=1$ ) and $E\left(\eta_{t}^{3}\right)=1 .{ }^{11}$ Fourth, based on $\{D F-W B(j)\}_{j=1}^{M}$, the bootstrap critical value $c_{\alpha}^{*}$ is selected as $c_{\alpha}^{*}=\max \left\{c: \sum_{j=1}^{M} I(D F-W B(j)<c) \leq \alpha\right\}$ where $I(\times)$ is an indicator function.

For the KSS test, the wild bootstrap procedure is fairly the same as that of the DF test described above. The only difference is, instead of using the DF statistic, the KSS statistic is employed.

\footnotetext{
${ }^{11}$ Cavaliere and Taylor (2008) suggested drawing $\eta_{t}$ from iid $\mathrm{N}(0,1)$ and claimed that the results are similar with the standard normal and the Liu-Mammen distribution. We find that this is only true when the linear DF test is considered. For the nonlinear KSS test, bootstrapping with the Liu-Mammen distribution clearly outperform the standard normal distribution.
} 


\section{References}

Adler, M., Lehmann (1983) Deviations from purchasing power parity in the long run, Journal of Finance 45, 157-174.

Arghyrou, M.G., Gregoriou, A. (2007) Testing for purchasing power parity correcting for nonnormality using the wild bootstrap, Economics Letters 95, 285-290.

Arghyrou, M.G., Gregoriou, A. (2008) Non-linearity versus non-normality in real exchange rate dynamics, Economics Letters 100, 200-203.

Bec, F., M.B. Salem and M. Carrasco (2004) Tests for unit-root versus threshold specification with an application to the purchasing power parity relationship, Journal of Business \& Economic Statistics 22, 382-395.

Bahmani-Oskooee, M., Nasir, A.B.M. (2005) Productivity bias hypothesis and the purchasing power parity: A review article, Journal of Economics Surveys 19, 671-696.

Bahmani-Oskooee, M., Hegerty, S.W., Kutan, A.M. (2007) Testing PPP in the non-linear STAR framework, Economics Letters 49, 104-110.

Bahmani-Oskooee, M., Hegerty, S.W., Kutan, A.M. (2009) Is PPP sensitive to time-varying trade weights in constructing real effective exchange rates?, The Quarterly Review of Economics and Finance 49, 1001-1008.

Busetti, F., Taylor, A.M.R. (2003) Testing against stochastic trend in the presence of variance-shifts, Journal of Business and Economic Statistics 21, 510-531.

Cassel, G. (1918) Abnormal deviations in international exchanges. Economic Journal 28, 413415.

Cassel, G. (1922) Money and foreign exchange after 1914, New York: Macmillan.

Cavaliere, G. (2004) Unit root tests under time-varying variances, Econometric Reviews 23, 259-296.

Cavaliere, G., Taylor, A.M.R. (2007) Testing for unit roots in time series models with nonstationary volatility, Journal of Econometrics 140, 919-947.

Cavaliere, G., Taylor, A.M.R. (2008) Bootstrap unit root tests for time series with nonstationary volatility, Econometric Theory 24, 43-71.

Cavaliere, G., Taylor, A.M.R. (2009) Bootstrap M unit root tests, Econometric Review 28, 393-421.

Cavaliere, G., Phillips, P.C.B., Smeekes, S. Taylor, A.M.R. (2013) Lag length selection for unit root tests in the presence of nonstationary volatility, Econometric Reviews (forthcoming).

Cook, S. (2006) GARCH, heteroscedasticity-consistent covariance matrix estimation and (non)linear unit root testing, Applied Financial Economics Letters 2, 217-222 
Dominguez, K. (1998) Central bank intervention and exchange rate volatility. Journal of International Money and Finance 17, 161-190.

Dumas, B. (1992) Dynamic equilibrium and the real exchange rate in a spatially separated world, Review of Financial Studies 5, 153-180.

Enders W. and C.W.J. Granger (1998) Unit-root tests and asymmetric adjustment with an example using the term structure of interest rates, Journal of Business \& Economic Statistics 16, 304-311.

Giacomini, R., Politis, D., White, H. (2013) A warp-speed method for conducting Monte Carlo experiments involving bootstrap estimators, Econometric Theory 29, 567-589.

Hamori, S., Tokihisa, A. (1997) Testing for a unit root in the presence of variance shift, Economics Letters 57, 245-253.

Hanck, C. (2012) On the asymptotic distribution of a unit root test against ESTAR alternatives, Statistics and Probability Letters 82, 360-364.

International Monetary Fund (2008), De Facto Classification of Exchange Rate Regimes and Monetary Policy cited at https://www.imf.org/external/np/mfd/er/2008/eng/0408.htm.

Kapetanios, G., Snell, A., Shin, Y. (2003) Testing for unit root in the nonlinear STAR framework, Journal of Econometrics 112, 359-379.

Kim, K., Schmidt, P. (1993) Unit root tests with conditional heteroskedasticity. Journal of Econometrics 59, 287-300.

Kim, T.H., Leybourne, S., Newbold, P. (2002) Unit root tests with a break in innovation variance, Journal of Econometrics 109, 365-387.

Klau, M., Fung, S.S. (2006) The new BIS effective exchange rate indices, BIS Quarterly Review (March), 51-65.

Krugman, P. (1991) Target zones and exchange rate dynamics. Quarterly Journal of Economics 106, 669-682.

Lee, H.Y. (2011) Nonlinear exchange rate dynamics under stochastic official intervention. Economic Modelling 28, 1510-1518.

Liew, V.K., Baharumshah, A.Z., Chong, T.T. (2004) Are Asian real exchange rates stationary? Economics Letters 83, 313-316.

Liu, R.Y. (1988) Bootstrap procedure under some non-I.I.D. models. The Annals of Statistics 16, 1696-1708.

Loretan, M., Phillips, P.C.B. (1994) Testing the covariance stationarity of heavy-tailed time series: An overview of the theory with applications to several financial datasets, Journal of Empirical Finance 1, 211-248. 
Mammen, E. (1993) Bootstrap and wild bootstrap for high dimensional linear models. The Annals of Statistics 21, 255-285.

Michael, P., Nobay, A.R., Peel, D.A. (1997) Transactions costs and nonlinear adjustment in real exchange rates: an empirical investigation. Journal of Political Economy 105, 862879.

$\mathrm{Ng}$, S. and Perron, P. (2001) Lag length selection and the construction of unit root tests with good size and power. Econometrica, 69, 1519-1554.

Obtstfeld, M. and Taylor, A. (1997) Nonlinear aspects of goods-market arbitrage and adjustment: Heckscher's commodity points revisited, Journal of the Japanese and International Economics 11, 441-479.

Palm, F.C., Smeekes, S., Urbain, J.-P. (2008) Bootstrap unit root tests: Comparison and extensions. Journal of Time Series Analysis 29, 371-401.

Perron, P., Qu, Z. (2007) A simple modification to improve the finite sample properties of $\mathrm{Ng}$ and Perron's unit root tests, Economics Letters 94, 12-19.

Pesaran, M.H., Smith, R.P., Yamagata, T., Hvozdyk, L. (2009) Pairwise tests of purchasing power parity. Econometric Reviews 28, 495-521.

Reitz, S., and Taylor, M. (2008) The coordination channel of foreign exchange intervention: a nonlinear microstructural analysis. European Economic Review 52, 55-76.

Rogoff, K. (1996) The purchasing power parity puzzle, Journal of Economic Literature 34, 647-668.

Sarno, L. and Taylor, M. (2002), Purchasing power parity and the real exchange rate, IMF Staff Papers, 49, 1, pp. 65-105.

Sercu, P., Uppal, R. and Van Hulle, C. (1995) The exchange rate in the presence of transactions costs: implications for tests of purchasing power parity, Journal of Finance 50, 1309-1319.

Smeekes, S. Taylor, A.M.R. (2011) Bootstrap union tests for unit roots in the presence of nonstationary volatility, Econometric Theory 28, 1-35.

Su, J.J. (2011) On oversized problem of Dickey-Fuller-type tests with GARCH errors, Communications in Statistics - Simulation and Computation 40, 1364-1372.

Su, J.J., Cheung, A.W-K., Roca, E. (2012) Lag selection of the augmented Kapetanios-ShinSnell (KSS) nonlinear unit root test, Journal of Mathematics and Statistics 9 (2): 102111.

Sollis, R. (2009) A simple unit root test against asymmetric STAR nonlinearity with an application to real exchange rates in Nordic countries, Economic Modelling 26, 118125. 
Taylor, A.M., 2001. Potential pitfalls for the purchasing power parity puzzle? Sampling and specification biases in mean-reversion tests of the law of one price. Econometrica 69, 473-498.

Taylor, A. and Taylor, M. (2004) The purchasing power parity debate, Journal of Economic Perspectives 18, 135-158.

Taylor, M. (2006), Purchasing Power Parity and Real Exchange Rate: Mean-Reversion in Economic Thought, Applied Financial Economics 16, pp. 1-17

Valkanov, R., 2005. Functional central limit theorem approximations and the distribution of the Dickey-Fuller test with strongly heteroskedastic data. Economics Letters 86, 427433.

White, H. (1980) A heteroscedasticity-consistent covariance matrix estimator and a direct test of heteroscedasticity, Econometrica 48, 817-38.

Wille, K. (2011). "Swiss Pledge Unlimited Currency Purchases". Bloomberg News, September 6, online, Bloomberg.com. Retrieved 2013-08-19. Available at http://www.bloomberg.com/news/2011-09-06/swiss-national-bank-sets-minimumexchange-rate-of-1-20-against-the-euro.html.

Zhou, S., Kutan, A. (2011) Is the evidence for PPP reliable? A sustainability examination of the stationarity of real exchange rates. Journal of Banking and Finance 35, 2479-2490.

Zussman, A. (2003) "The limits of arbitrage: trading frictions and deviations from purchasing power parity." SIEPR Policy Paper No. 02-012. 
Table 1: Size at $5 \%$ significance level

Case A: Level

\begin{tabular}{|c|c|c|c|c|c|c|c|c|}
\hline & $T=100$ & & & & $T=250$ & & & \\
\hline Volatility & KSS & KSS-WB & DF & DF-WB & KSS & KSS-WB & DF & DF-WB \\
\hline No Break & 0.051 & 0.050 & 0.050 & 0.050 & 0.049 & 0.050 & 0.050 & 0.050 \\
\hline GARCH[1] $\left(\phi_{1}=0.29, \phi_{2}=0.7\right)$ & 0.146 & 0.050 & 0.092 & 0.051 & 0.187 & 0.052 & 0.100 & 0.051 \\
\hline $\operatorname{GARCH}[2]\left(\phi_{1}=0.2, \phi_{2}=0.7\right)$ & 0.093 & 0.049 & 0.066 & 0.050 & 0.093 & 0.049 & 0.062 & 0.049 \\
\hline GARCH[3] $\left(\phi_{1}=0.19, \phi_{2}=0.8\right)$ & 0.116 & 0.052 & 0.079 & 0.052 & 0.148 & 0.048 & 0.087 & 0.051 \\
\hline GARCH[4] $\left(\phi_{1}=0.1, \phi_{2}=0.8\right)$ & 0.067 & 0.049 & 0.057 & 0.050 & 0.065 & 0.050 & 0.053 & 0.049 \\
\hline $\operatorname{SV}[1](b=2, c=0)$ & 0.247 & 0.051 & 0.159 & 0.048 & 0.261 & 0.049 & 0.161 & 0.049 \\
\hline $\operatorname{SV}[2](b=2, c=10)$ & 0.099 & 0.048 & 0.064 & 0.054 & 0.099 & 0.047 & 0.064 & 0.049 \\
\hline $\mathrm{SB}[1](\delta=1 / 2, \tau=0.2)$ & 0.103 & 0.051 & 0.091 & 0.051 & 0.101 & 0.052 & 0.093 & 0.054 \\
\hline $\mathrm{SB}[2](\delta=1 / 2, \tau=0.8)$ & 0.058 & 0.046 & 0.056 & 0.048 & 0.060 & 0.048 & 0.057 & 0.049 \\
\hline $\mathrm{SB}[3](\delta=2, \tau=0.2)$ & 0.036 & 0.052 & 0.033 & 0.049 & 0.035 & 0.048 & 0.032 & 0.049 \\
\hline $\mathrm{SB}[4](\delta=2, \tau=0.8)$ & 0.050 & 0.050 & 0.043 & 0.049 & 0.052 & 0.052 & 0.046 & 0.050 \\
\hline $\mathrm{SB}[5](\delta=1 / 5, \tau=0.2)$ & 0.262 & 0.049 & 0.196 & 0.052 & 0.281 & 0.053 & 0.202 & 0.050 \\
\hline $\mathrm{SB}[6](\delta=1 / 5, \tau=0.8)$ & 0.074 & 0.049 & 0.062 & 0.049 & 0.077 & 0.049 & 0.069 & 0.052 \\
\hline $\mathrm{SB}[7](\delta=5, \tau=0.2)$ & 0.038 & 0.051 & 0.024 & 0.053 & 0.036 & 0.049 & 0.025 & 0.051 \\
\hline $\mathrm{SB}[8](\delta=5, \tau=0.8)$ & 0.098 & 0.051 & 0.050 & 0.051 & 0.102 & 0.052 & 0.050 & 0.052 \\
\hline $\mathrm{DB}[1](\delta=1 / 2, \tau=0.2)$ & 0.086 & 0.047 & 0.077 & 0.052 & 0.089 & 0.050 & 0.081 & 0.050 \\
\hline $\mathrm{DB}[2](\delta=2, \tau=0.2)$ & 0.041 & 0.052 & 0.035 & 0.051 & 0.041 & 0.049 & 0.036 & 0.047 \\
\hline $\mathrm{DB}[3](\delta=1 / 5, \tau=0.2)$ & 0.167 & 0.049 & 0.134 & 0.049 & 0.170 & 0.050 & 0.130 & 0.048 \\
\hline $\mathrm{DB}[4](\delta=5, \tau=0.2)$ & 0.053 & 0.052 & 0.031 & 0.050 & 0.052 & 0.049 & 0.032 & 0.048 \\
\hline $\operatorname{TV}[1](\delta=1 / 2)$ & 0.071 & 0.051 & 0.066 & 0.051 & 0.076 & 0.052 & 0.069 & 0.050 \\
\hline $\operatorname{TV}[2](\delta=2)$ & 0.039 & 0.050 & 0.035 & 0.048 & 0.040 & 0.049 & 0.038 & 0.050 \\
\hline $\operatorname{TV}[3](\delta=1 / 5)$ & 0.120 & 0.051 & 0.102 & 0.053 & 0.122 & 0.051 & 0.099 & 0.050 \\
\hline $\operatorname{TV}[4](\delta=5)$ & 0.043 & 0.049 & 0.032 & 0.051 & 0.041 & 0.048 & 0.030 & 0.047 \\
\hline
\end{tabular}

Case B: Trend

\begin{tabular}{|c|c|c|c|c|c|c|c|c|}
\hline & $T=100$ & & & & $T=250$ & & & \\
\hline Volatility & KSS & KSS-WB & $\mathrm{DF}$ & DF-WB & KSS & KSS-WB & DF & DF-WB \\
\hline No Break & 0.050 & 0.050 & 0.051 & 0.048 & 0.051 & 0.048 & 0.051 & 0.051 \\
\hline GARCH[1] $\left(\phi_{1}=0.29, \phi_{2}=0.7\right)$ & 0.156 & 0.048 & 0.088 & 0.049 & 0.225 & 0.050 & 0.105 & 0.052 \\
\hline GARCH[2] $\left(\phi_{1}=0.2, \phi_{2}=0.7\right)$ & 0.104 & 0.053 & 0.070 & 0.053 & 0.119 & 0.049 & 0.068 & 0.048 \\
\hline GARCH[3] $\left(\phi_{1}=0.19, \phi_{2}=0.8\right)$ & 0.117 & 0.048 & 0.077 & 0.048 & 0.170 & 0.053 & 0.090 & 0.050 \\
\hline GARCH[4] $\left(\phi_{1}=0.1, \phi_{2}=0.8\right)$ & 0.069 & 0.048 & 0.056 & 0.047 & 0.081 & 0.052 & 0.058 & 0.052 \\
\hline $\operatorname{SV}[1](b=2, c=0)$ & 0.251 & 0.052 & 0.145 & 0.051 & 0.280 & 0.051 & 0.149 & 0.053 \\
\hline $\operatorname{SV}[2](b=2, c=10)$ & 0.117 & 0.050 & 0.068 & 0.050 & 0.120 & 0.049 & 0.065 & 0.051 \\
\hline $\mathrm{SB}[1](\delta=1 / 2, \tau=0.2)$ & 0.089 & 0.048 & 0.079 & 0.049 & 0.094 & 0.052 & 0.077 & 0.051 \\
\hline $\mathrm{SB}[2](\delta=1 / 2, \tau=0.8)$ & 0.059 & 0.049 & 0.058 & 0.049 & 0.060 & 0.052 & 0.055 & 0.052 \\
\hline $\mathrm{SB}[3](\delta=2, \tau=0.2)$ & 0.042 & 0.049 & 0.040 & 0.049 & 0.044 & 0.051 & 0.038 & 0.050 \\
\hline $\mathrm{SB}[4](\delta=2, \tau=0.8)$ & 0.056 & 0.051 & 0.050 & 0.053 & 0.054 & 0.050 & 0.048 & 0.051 \\
\hline $\mathrm{SB}[5](\delta=1 / 5, \tau=0.2)$ & 0.227 & 0.047 & 0.154 & 0.049 & 0.255 & 0.050 & 0.160 & 0.049 \\
\hline $\mathrm{SB}[6](\delta=1 / 5, \tau=0.8)$ & 0.075 & 0.049 & 0.063 & 0.049 & 0.078 & 0.049 & 0.065 & 0.051 \\
\hline $\mathrm{SB}[7](\delta=5, \tau=0.2)$ & 0.047 & 0.050 & 0.036 & 0.049 & 0.047 & 0.050 & 0.034 & 0.048 \\
\hline $\mathrm{SB}[8](\delta=5, \tau=0.8)$ & 0.113 & 0.049 & 0.057 & 0.050 & 0.123 & 0.050 & 0.055 & 0.046 \\
\hline $\mathrm{DB}[1](\delta=1 / 2, \tau=0.2)$ & 0.077 & 0.052 & 0.067 & 0.048 & 0.082 & 0.047 & 0.068 & 0.049 \\
\hline $\mathrm{DB}[2](\delta=2, \tau=0.2)$ & 0.048 & 0.049 & 0.041 & 0.048 & 0.050 & 0.049 & 0.044 & 0.051 \\
\hline $\mathrm{DB}[3](\delta=1 / 5, \tau=0.2)$ & 0.159 & 0.051 & 0.110 & 0.050 & 0.157 & 0.047 & 0.103 & 0.047 \\
\hline $\mathrm{DB}[4](\delta=5, \tau=0.2)$ & 0.072 & 0.052 & 0.045 & 0.051 & 0.073 & 0.052 & 0.043 & 0.051 \\
\hline $\operatorname{TV}[1](\delta=1 / 2)$ & 0.067 & 0.048 & 0.062 & 0.048 & 0.067 & 0.048 & 0.065 & 0.051 \\
\hline $\operatorname{TV}[2](\delta=2)$ & 0.044 & 0.051 & 0.044 & 0.050 & 0.046 & 0.049 & 0.043 & 0.050 \\
\hline $\operatorname{TV}[3](\delta=1 / 5)$ & 0.104 & 0.049 & 0.086 & 0.048 & 0.103 & 0.047 & 0.087 & 0.053 \\
\hline TV[4] $(\delta=5)$ & 0.053 & 0.052 & 0.039 & 0.053 & 0.053 & 0.053 & 0.038 & 0.054 \\
\hline
\end{tabular}


Table 2: Power at 5\% significance level (Note: DF \& KSS are with size-corrected power.)

Case A: Level

\begin{tabular}{|c|c|c|c|c|c|c|c|c|c|}
\hline & & $T=100$ & & & & $T=250$ & & & \\
\hline DGP & Volatility & KSS & KSS-WB & DF & DF-WB & KSS & KSS-WB & DF & DF-WB \\
\hline AR & No Break & 0.254 & 0.261 & 0.327 & 0.338 & 0.740 & 0.736 & 0.972 & 0.972 \\
\hline \multirow[t]{8}{*}{$(\rho=0.9)$} & GARCH [1] $\left(\phi_{1}=0.29, \phi_{2}=0.7\right)$ & 0.173 & 0.175 & 0.233 & 0.232 & 0.399 & 0.386 & 0.823 & 0.800 \\
\hline & GARCH[2] $\left(\phi_{1}=0.2, \phi_{2}=0.7\right)$ & 0.220 & 0.233 & 0.294 & 0.302 & 0.598 & 0.594 & 0.927 & 0.921 \\
\hline & $\operatorname{SV}[1](b=2, c=0)$ & 0.086 & 0.089 & 0.112 & 0.113 & 0.217 & 0.217 & 0.514 & 0.530 \\
\hline & $\operatorname{SV}[2](b=2, c=10)$ & 0.200 & 0.206 & 0.307 & 0.304 & 0.587 & 0.587 & 0.922 & 0.923 \\
\hline & $\mathrm{SB}[1](\delta=1 / 2, \tau=0.2)$ & 0.163 & 0.159 & 0.227 & 0.221 & 0.580 & 0.572 & 0.902 & 0.893 \\
\hline & $\mathrm{SB}[3](\delta=2, \tau=0.2)$ & 0.333 & 0.323 & 0.434 & 0.423 & 0.784 & 0.788 & 0.986 & 0.984 \\
\hline & $\operatorname{TV}[1](\delta=1 / 2)$ & 0.201 & 0.200 & 0.268 & 0.268 & 0.661 & 0.660 & 0.940 & 0.942 \\
\hline & $\operatorname{TV}[2](\delta=2)$ & 0.300 & 0.298 & 0.389 & 0.384 & 0.764 & 0.760 & 0.975 & 0.977 \\
\hline ESTAR[1] & No Break & 0.487 & 0.478 & 0.317 & 0.333 & 0.991 & 0.991 & 0.999 & 0.999 \\
\hline$(\theta=0.01)$ & GARCH [1] $\left(\phi_{1}=0.29, \phi_{2}=0.7\right)$ & 0.204 & 0.199 & 0.160 & 0.160 & 0.518 & 0.504 & 0.517 & 0.499 \\
\hline \multirow[t]{7}{*}{$(\gamma=-0.1)$} & GARCH[2] $\left(\phi_{1}=0.2, \phi_{2}=0.7\right)$ & 0.416 & 0.393 & 0.309 & 0.286 & 0.965 & 0.957 & 0.988 & 0.987 \\
\hline & $\operatorname{SV}[1](b=2, c=0)$ & 0.469 & 0.428 & 0.463 & 0.438 & 0.763 & 0.732 & 0.748 & 0.735 \\
\hline & $\operatorname{SV}[2](b=2, c=10)$ & 0.566 & 0.522 & 0.497 & 0.467 & 0.985 & 0.981 & 0.994 & 0.993 \\
\hline & $\mathrm{SB}[1](\delta=1 / 2, \tau=0.2)$ & 0.211 & 0.197 & 0.150 & 0.139 & 0.876 & 0.861 & 0.817 & 0.781 \\
\hline & $\mathrm{SB}[3](\delta=2, \tau=0.2)$ & 0.807 & 0.788 & 0.745 & 0.720 & 1.000 & 1.000 & 1.000 & 1.000 \\
\hline & $\operatorname{TV}[1](\delta=1 / 2)$ & 0.296 & 0.311 & 0.195 & 0.200 & 0.954 & 0.953 & 0.957 & 0.962 \\
\hline & $\operatorname{TV}[2](\delta=2)$ & 0.707 & 0.688 & 0.575 & 0.582 & 0.999 & 0.998 & 1.000 & 1.000 \\
\hline ESTAR[2] & No Break & 0.233 & 0.232 & 0.176 & 0.178 & 0.885 & 0.888 & 0.855 & 0.841 \\
\hline$(\theta=0.01)$ & GARCH [1] $\left(\phi_{1}=0.29, \phi_{2}=0.7\right)$ & 0.135 & 0.132 & 0.108 & 0.112 & 0.339 & 0.311 & 0.329 & 0.310 \\
\hline \multirow[t]{7}{*}{$(\gamma=-0.5)$} & GARCH[2] $\left(\phi_{1}=0.2, \phi_{2}=0.7\right)$ & 0.226 & 0.227 & 0.169 & 0.174 & 0.790 & 0.775 & 0.774 & 0.762 \\
\hline & $\operatorname{SV}[1](b=2, c=0)$ & 0.249 & 0.222 & 0.314 & 0.303 & 0.595 & 0.575 & 0.610 & 0.607 \\
\hline & $\operatorname{SV}[2](b=2, c=10)$ & 0.308 & 0.279 & 0.233 & 0.221 & 0.884 & 0.874 & 0.895 & 0.896 \\
\hline & $\mathrm{SB}[1](\delta=1 / 2, \tau=0.2)$ & 0.114 & 0.111 & 0.103 & 0.096 & 0.532 & 0.525 & 0.362 & 0.360 \\
\hline & $\mathrm{SB}[3](\delta=2, \tau=0.2)$ & 0.498 & 0.483 & 0.372 & 0.369 & 0.984 & 0.985 & 0.999 & 0.999 \\
\hline & $\operatorname{TV}[1](\delta=1 / 2)$ & 0.153 & 0.156 & 0.129 & 0.134 & 0.714 & 0.709 & 0.542 & 0.547 \\
\hline & $\operatorname{TV}[2](\delta=2)$ & 0.397 & 0.374 & 0.279 & 0.274 & 0.970 & 0.968 & 0.985 & 0.985 \\
\hline
\end{tabular}

Case B: Trend

\begin{tabular}{|c|c|c|c|c|c|c|c|c|c|}
\hline & & $T=100$ & & & & $T=250$ & & & \\
\hline DGP & Volatility & KSS & KSS-WB & DF & DF-WB & KSS & KSS-WB & DF & DF-WB \\
\hline AR & No Break & 0.158 & 0.159 & 0.196 & 0.202 & 0.551 & 0.549 & 0.840 & 0.844 \\
\hline \multirow[t]{8}{*}{$(\rho=0.9)$} & GARCH [1] $\left(\phi_{1}=0.29, \phi_{2}=0.7\right)$ & 0.115 & 0.120 & 0.153 & 0.151 & 0.258 & 0.247 & 0.623 & 0.613 \\
\hline & $\operatorname{GARCH}[2]\left(\phi_{1}=0.2, \phi_{2}=0.7\right)$ & 0.138 & 0.144 & 0.170 & 0.180 & 0.400 & 0.414 & 0.757 & 0.783 \\
\hline & $S V[1](b=2, c=0)$ & 0.073 & 0.070 & 0.089 & 0.091 & 0.159 & 0.163 & 0.417 & 0.419 \\
\hline & $\operatorname{SV}[2](b=2, c=10)$ & 0.115 & 0.123 & 0.173 & 0.174 & 0.395 & 0.390 & 0.763 & 0.768 \\
\hline & $\mathrm{SB}[1](\delta=1 / 2, \tau=0.2)$ & 0.124 & 0.121 & 0.155 & 0.168 & 0.443 & 0.454 & 0.752 & 0.765 \\
\hline & $\mathrm{SB}[3](\delta=2, \tau=0.2)$ & 0.166 & 0.168 & 0.216 & 0.215 & 0.573 & 0.573 & 0.867 & 0.871 \\
\hline & $\operatorname{TV}[1](\delta=1 / 2)$ & 0.130 & 0.129 & 0.173 & 0.171 & 0.500 & 0.481 & 0.811 & 0.805 \\
\hline & $\operatorname{TV}[2](\delta=2)$ & 0.167 & 0.176 & 0.210 & 0.211 & 0.552 & 0.559 & 0.859 & 0.858 \\
\hline ESTAR[1] & No Break & 0.279 & 0.261 & 0.204 & 0.200 & 0.941 & 0.940 & 0.948 & 0.958 \\
\hline$(\theta=0.01)$ & GARCH [1] $\left(\phi_{1}=0.29, \phi_{2}=0.7\right)$ & 0.156 & 0.145 & 0.129 & 0.123 & 0.383 & 0.347 & 0.394 & 0.366 \\
\hline \multirow[t]{7}{*}{$(\gamma=-0.1)$} & GARCH[2] $\left(\phi_{1}=0.2, \phi_{2}=0.7\right)$ & 0.262 & 0.252 & 0.200 & 0.201 & 0.839 & 0.817 & 0.882 & 0.875 \\
\hline & $S V[1](b=2, c=0)$ & 0.425 & 0.374 & 0.454 & 0.438 & 0.702 & 0.660 & 0.731 & 0.702 \\
\hline & $\operatorname{SV}[2](b=2, c=10)$ & 0.367 & 0.320 & 0.325 & 0.299 & 0.927 & 0.909 & 0.957 & 0.956 \\
\hline & $\mathrm{SB}[1](\delta=1 / 2, \tau=0.2)$ & 0.147 & 0.141 & 0.126 & 0.127 & 0.677 & 0.659 & 0.561 & 0.571 \\
\hline & $\mathrm{SB}[3](\delta=2, \tau=0.2)$ & 0.528 & 0.509 & 0.406 & 0.415 & 0.997 & 0.996 & 1.000 & 1.000 \\
\hline & $\operatorname{TV}[1](\delta=1 / 2)$ & 0.189 & 0.180 & 0.155 & 0.151 & 0.832 & 0.815 & 0.773 & 0.769 \\
\hline & $\operatorname{TV}[2](\delta=2)$ & 0.437 & 0.419 & 0.321 & 0.319 & 0.987 & 0.987 & 0.998 & 0.999 \\
\hline ESTAR[2] & No Break & 0.144 & 0.142 & 0.127 & 0.123 & 0.643 & 0.641 & 0.547 & 0.545 \\
\hline$(\theta=0.01)$ & GARCH [1] $\left(\phi_{1}=0.29, \phi_{2}=0.7\right)$ & 0.106 & 0.102 & 0.095 & 0.093 & 0.251 & 0.233 & 0.250 & 0.238 \\
\hline \multirow[t]{7}{*}{$(\gamma=-0.5)$} & GARCH[2] $\left(\phi_{1}=0.2, \phi_{2}=0.7\right)$ & 0.150 & 0.148 & 0.120 & 0.126 & 0.528 & 0.523 & 0.499 & 0.516 \\
\hline & $\operatorname{SV}[1](b=2, c=0)$ & 0.207 & 0.183 & 0.289 & 0.279 & 0.516 & 0.493 & 0.592 & 0.572 \\
\hline & $\operatorname{SV}[2](b=2, c=10)$ & 0.182 & 0.173 & 0.167 & 0.158 & 0.695 & 0.671 & 0.714 & 0.702 \\
\hline & $\mathrm{SB}[1](\delta=1 / 2, \tau=0.2)$ & 0.095 & 0.092 & 0.091 & 0.089 & 0.318 & 0.325 & 0.249 & 0.268 \\
\hline & $\mathrm{SB}[3](\delta=2, \tau=0.2)$ & 0.248 & 0.243 & 0.197 & 0.198 & 0.909 & 0.898 & 0.922 & 0.918 \\
\hline & $\operatorname{TV}[1](\delta=1 / 2)$ & 0.108 & 0.102 & 0.105 & 0.106 & 0.460 & 0.450 & 0.353 & 0.342 \\
\hline & $\operatorname{TV}[2](\delta=2)$ & 0.204 & 0.201 & 0.165 & 0.169 & 0.836 & 0.837 & 0.814 & 0.811 \\
\hline
\end{tabular}


Table 3 (a): Empirical results on 61 Real Effective Exchange Rates (Constant Mean)

\begin{tabular}{|c|c|c|c|c|c|c|}
\hline Currency & ADF & A. P-value & WB p-value & KSS & A. P-value & WB p-value \\
\hline Algeria & -4.608 & $0.000 * * *$ & $0.023 * *$ & -15.718 & $0.000 * * *$ & $0.000^{* * *}$ \\
\hline Argentina & -1.319 & 0.624 & 0.484 & -2.200 & 0.256 & 0.202 \\
\hline Australia & -0.871 & 0.799 & 0.734 & -1.048 & 0.823 & 0.750 \\
\hline Austria & -1.810 & 0.376 & 0.494 & -2.236 & 0.240 & 0.413 \\
\hline Belgium & -1.699 & 0.433 & 0.473 & -2.046 & 0.331 & 0.381 \\
\hline Brazil & -1.578 & 0.495 & 0.450 & -2.240 & 0.238 & 0.274 \\
\hline Bulgaria & -1.763 & 0.399 & 0.928 & -5.091 & $0.000 * * *$ & 0.271 \\
\hline Canada & -0.867 & 0.800 & 0.694 & -1.744 & 0.505 & 0.439 \\
\hline Chile & -2.268 & 0.185 & 0.151 & -1.882 & 0.424 & 0.387 \\
\hline China & -2.584 & $0.097^{*}$ & 0.114 & -2.787 & $0.072^{*}$ & $0.083^{*}$ \\
\hline Chinese Taipei (Taiwan) & -1.334 & 0.617 & 0.673 & -2.062 & 0.323 & 0.324 \\
\hline Colombia & -1.687 & 0.439 & 0.385 & -1.563 & 0.609 & 0.572 \\
\hline Croatia & -1.799 & 0.381 & 0.441 & -1.783 & 0.481 & 0.552 \\
\hline Cyprus & -1.397 & 0.587 & 0.657 & -2.706 & $0.089 *$ & 0.116 \\
\hline Czech Republic & -1.324 & 0.622 & 0.579 & -1.962 & 0.378 & 0.323 \\
\hline Denmark & -2.117 & 0.239 & 0.233 & -2.418 & 0.168 & 0.194 \\
\hline Estonia & -4.022 & $0.001 * * *$ & $0.018 * *$ & -4.377 & $0.000 * * *$ & $0.009 * * *$ \\
\hline Euro area & -1.745 & 0.409 & 0.343 & -1.943 & 0.388 & 0.324 \\
\hline Finland & -2.140 & 0.231 & 0.326 & -2.147 & 0.280 & 0.467 \\
\hline France & -1.363 & 0.604 & 0.622 & -1.931 & 0.395 & 0.447 \\
\hline Germany & -1.458 & 0.556 & 0.539 & -1.814 & 0.463 & 0.477 \\
\hline Greece & -1.501 & 0.535 & 0.588 & -1.834 & 0.451 & 0.483 \\
\hline Hong Kong SAR & -0.543 & 0.881 & 0.838 & -1.754 & 0.499 & 0.438 \\
\hline Hungary & -0.905 & 0.788 & 0.688 & -1.655 & 0.558 & 0.530 \\
\hline Iceland & -1.279 & 0.643 & 0.428 & -2.703 & $0.089 *$ & 0.286 \\
\hline India & -2.551 & 0.104 & 0.119 & -2.573 & 0.120 & 0.107 \\
\hline Indonesia & -2.579 & $0.098 *$ & $0.091^{*}$ & -4.525 & $0.000 * * *$ & 0.154 \\
\hline Ireland & -1.395 & 0.588 & 0.558 & -1.742 & 0.506 & 0.446 \\
\hline Israel & -1.279 & 0.643 & 0.634 & -1.496 & 0.645 & 0.576 \\
\hline Italy & -2.129 & 0.235 & 0.530 & -4.258 & $0.000 * * *$ & 0.120 \\
\hline Japan & -1.843 & 0.361 & 0.385 & -2.116 & 0.295 & 0.296 \\
\hline Korea & -2.480 & 0.122 & $0.076^{*}$ & -3.232 & $0.021 * *$ & $0.082^{*}$ \\
\hline Latvia & -2.515 & 0.113 & 0.154 & -2.490 & 0.144 & 0.208 \\
\hline Lithuania & -4.102 & $0.000 * * *$ & $0.010 * * *$ & -3.867 & $0.002 * * *$ & $0.060 *$ \\
\hline Luxembourg & -1.637 & 0.465 & 0.502 & -1.884 & 0.423 & 0.496 \\
\hline Malaysia & -2.065 & 0.260 & 0.415 & -2.074 & 0.316 & 0.590 \\
\hline Malta & -1.537 & 0.516 & 0.464 & -1.359 & 0.712 & 0.573 \\
\hline Mexico & -2.266 & 0.186 & 0.577 & -4.241 & $0.000 * * *$ & 0.507 \\
\hline Netherlands & -1.715 & 0.424 & 0.450 & -2.113 & 0.297 & 0.339 \\
\hline New Zealand & -1.705 & 0.430 & 0.296 & -2.224 & 0.245 & 0.180 \\
\hline Norway & -1.626 & 0.470 & 0.404 & -2.695 & 0.091* & 0.102 \\
\hline Peru & -1.794 & 0.384 & 0.415 & -2.134 & 0.287 & 0.344 \\
\hline Philippines & -1.543 & 0.513 & 0.628 & -1.450 & 0.669 & 0.795 \\
\hline Poland & -2.431 & 0.134 & $0.081^{*}$ & -1.970 & 0.373 & 0.289 \\
\hline Portugal & -0.963 & 0.769 & 0.780 & -1.785 & 0.480 & 0.460 \\
\hline Romania & -1.775 & 0.393 & 0.676 & -4.425 & $0.000 * * *$ & $0.080^{*}$ \\
\hline Russia & -1.934 & 0.317 & 0.512 & -2.846 & $0.062^{*}$ & 0.343 \\
\hline Saudi Arabia & -1.466 & 0.552 & 0.515 & -1.936 & 0.392 & 0.370 \\
\hline Singapore & -0.750 & 0.833 & 0.830 & -0.657 & 0.892 & 0.878 \\
\hline Slovakia & -0.572 & 0.875 & 0.935 & -0.844 & 0.864 & 0.903 \\
\hline Slovenia & -1.872 & 0.346 & 0.364 & -2.016 & 0.347 & 0.415 \\
\hline South Africa & -2.478 & 0.122 & $0.066^{*}$ & -2.951 & $0.048^{*}$ & $0.041 * *$ \\
\hline Spain & -1.141 & 0.703 & 0.717 & -2.109 & 0.298 & 0.385 \\
\hline Sweden & -2.100 & 0.246 & 0.266 & -2.614 & 0.109 & 0.118 \\
\hline Switzerland & -2.042 & 0.269 & 0.301 & -4.399 & $0.000 * * *$ & $0.011 * *$ \\
\hline Thailand & -2.551 & 0.104 & 0.145 & -7.548 & $0.000 * * *$ & $0.005^{* * *}$ \\
\hline Turkey & -2.250 & 0.191 & 0.217 & -2.952 & $0.047 * *$ & 0.229 \\
\hline United Arab Emirates & -1.714 & 0.425 & 0.374 & -1.461 & 0.664 & 0.587 \\
\hline United Kingdom & -1.139 & 0.704 & 0.623 & -2.573 & 0.120 & 0.132 \\
\hline United States & -0.935 & 0.778 & 0.749 & -1.299 & 0.739 & 0.718 \\
\hline Venezuela & -1.746 & 0.408 & 0.367 & -2.973 & $0.045^{* *}$ & 0.102 \\
\hline
\end{tabular}


Table 3 (b): Empirical results on 61 Real Effective Exchange Rates (Linear Trend)

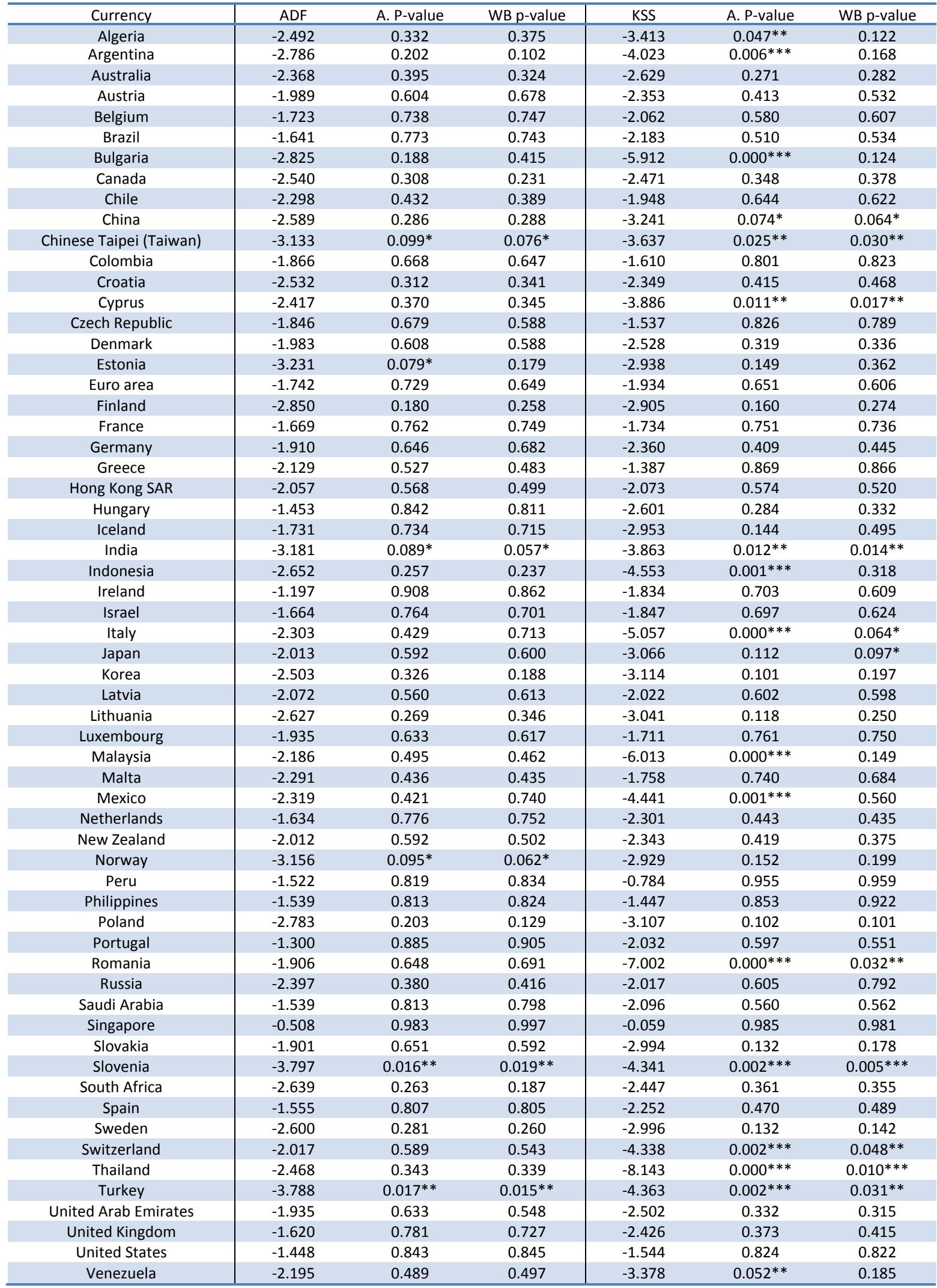

Note: ${ }^{*}, * *$ and $* * *$ denote rejection at $10 \%, 5 \%$ and $1 \%$, respectively, using the asymptotic $p$-value (A. $p$-value) and wild bootstrap p-value (WB p-value). 
Figure 1: Variance Profile for 61 Real Effective Exchange Rates

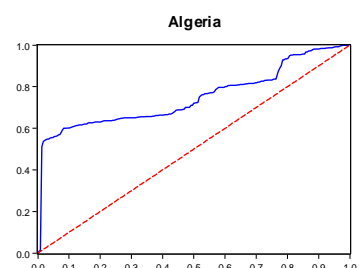

Belgium

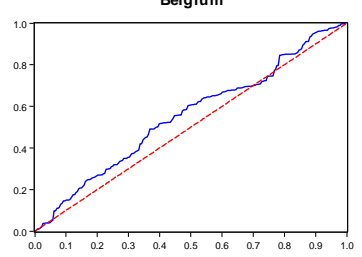

Chile

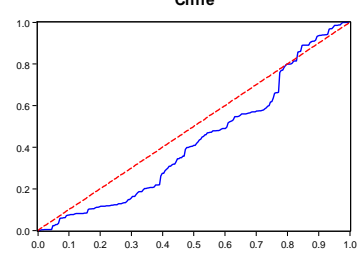

croatia

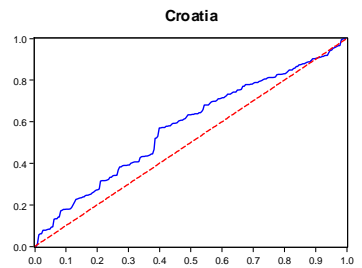

Estonia

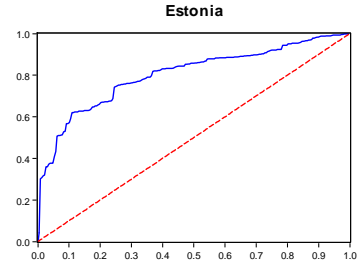

Germany

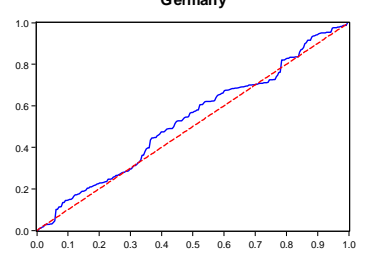

Iceland
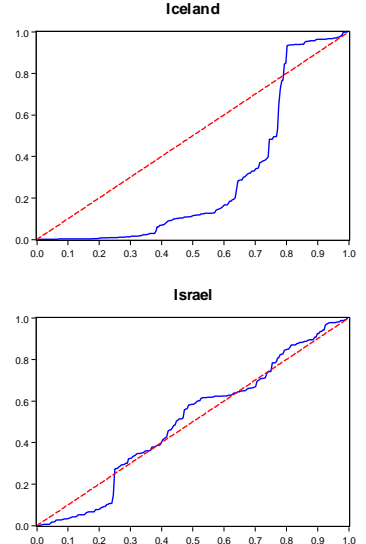

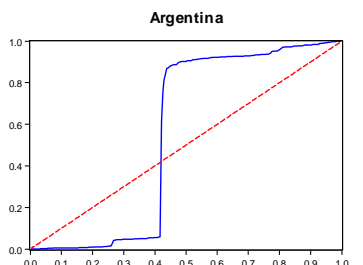

Brazil

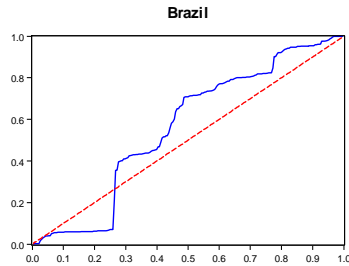

Chin

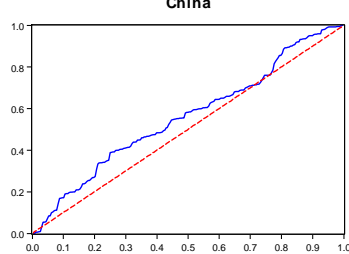

Cyprus

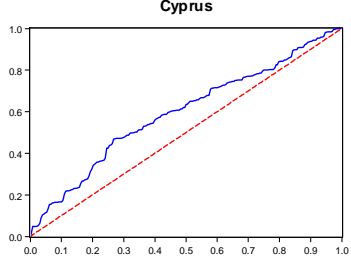

Euro_Area

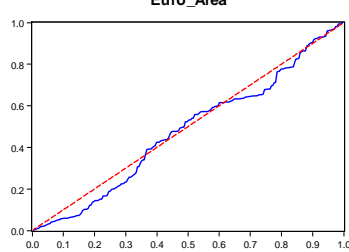

Greece

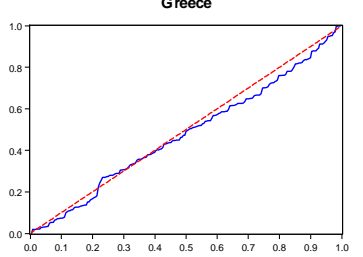

India

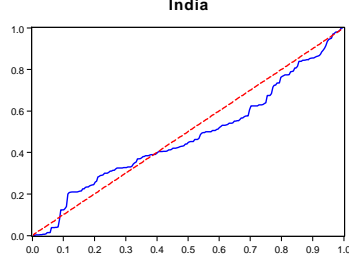

Italy

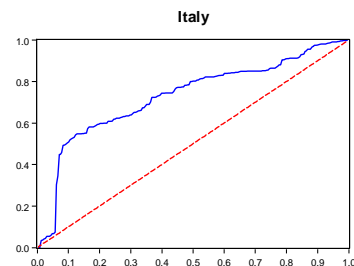

Australia

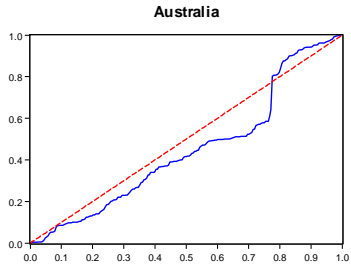

Bulgaria

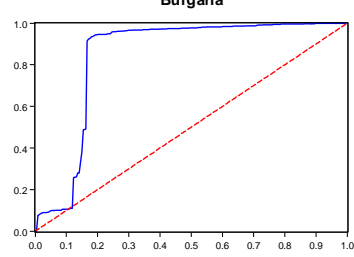

Chinese_Taipei

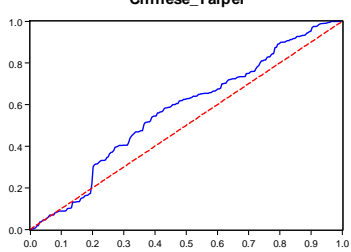

Czech_Republic

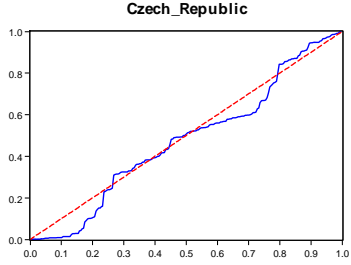

Finland

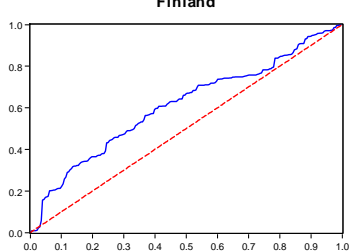

Hong Kong

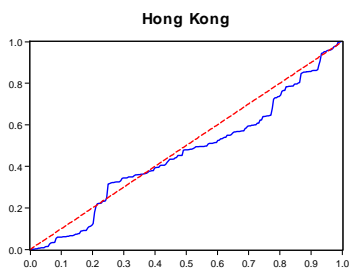

Indonesia

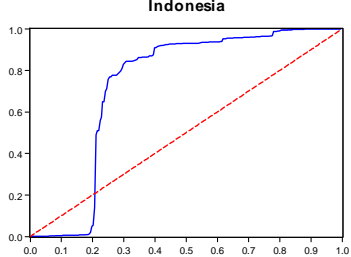

Japan

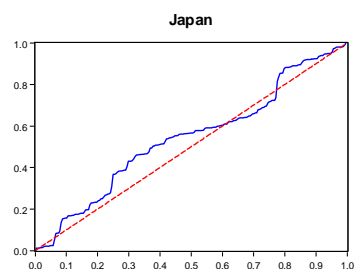

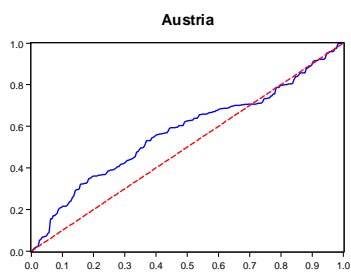

Canada

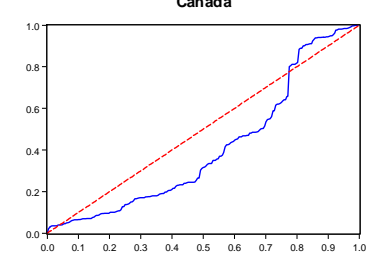

Colombia

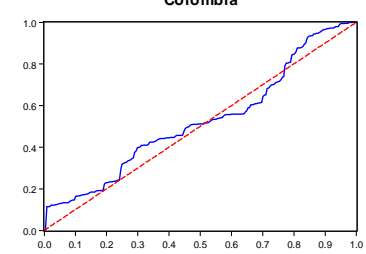

Denmark

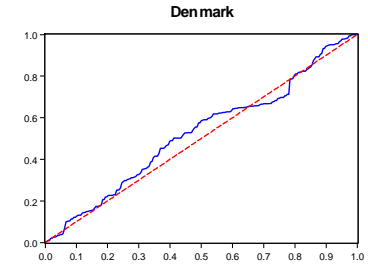

France

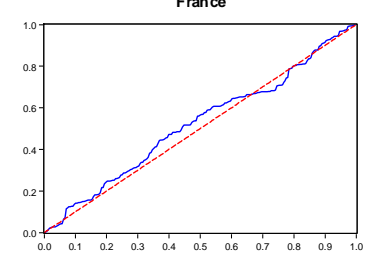

Hungary

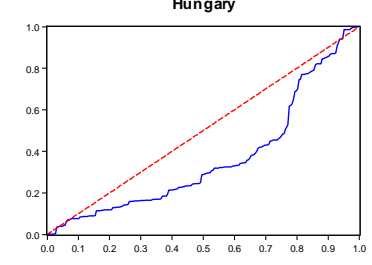

Ireland

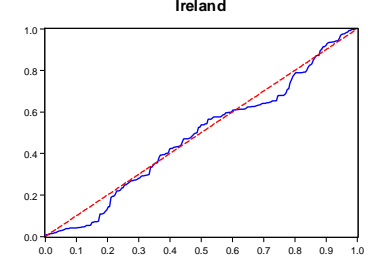

Korea

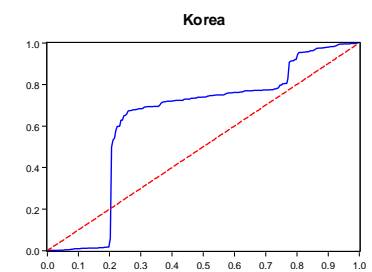


Figure 1: Variance Profile for 61 Real Effective Exchange Rates (continued)
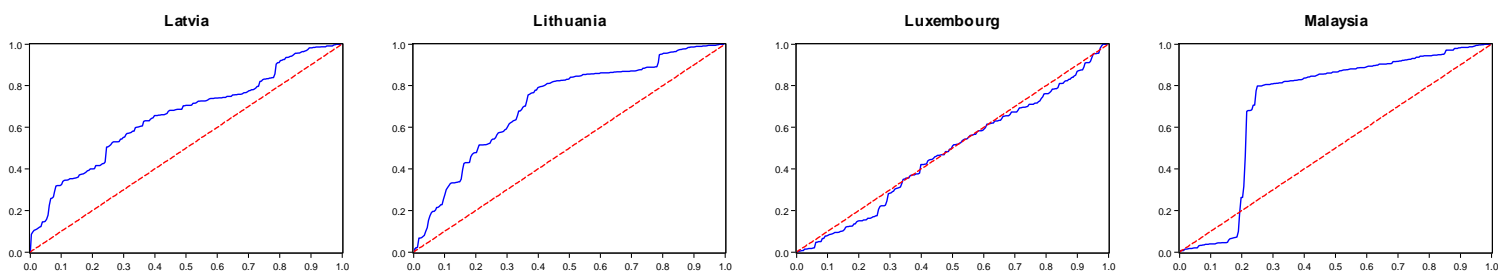

Malta

Mexico
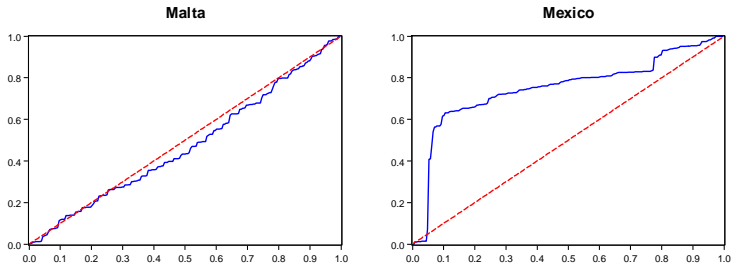

Netherlands

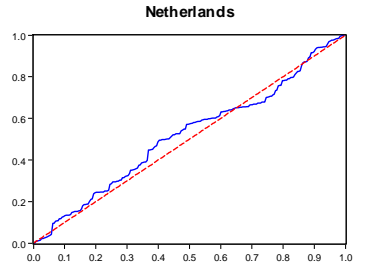

Norway

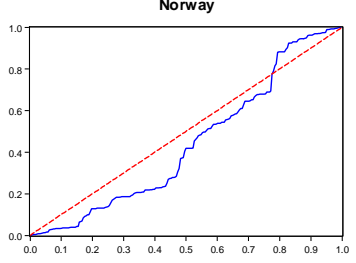

Peru

Philippines
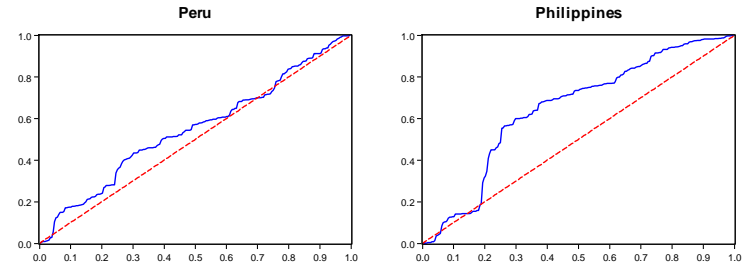

Romania
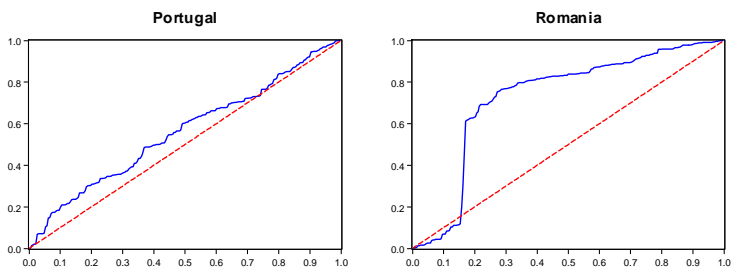

Slovakia
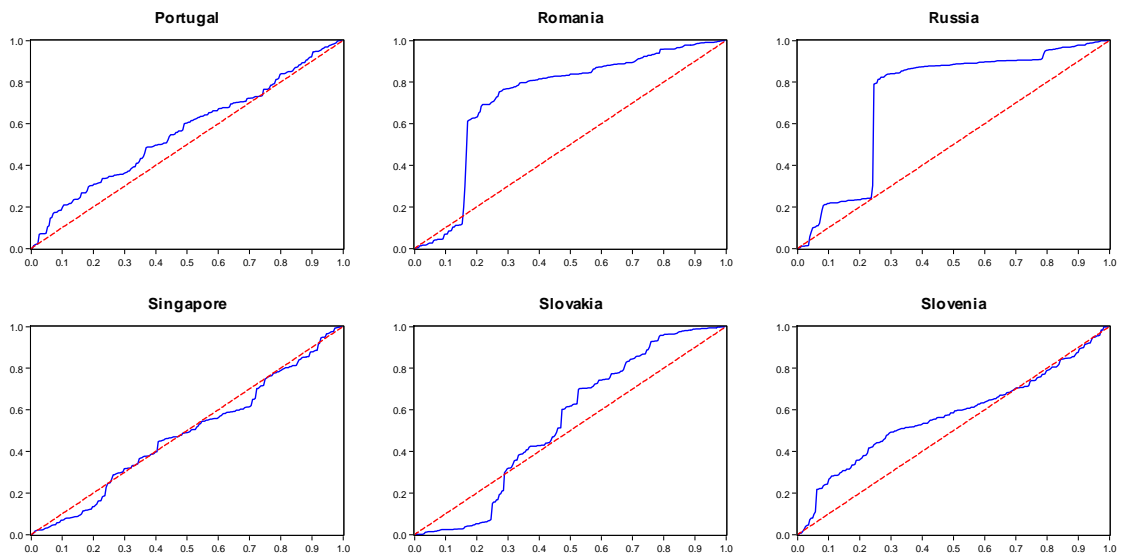

Slovenia

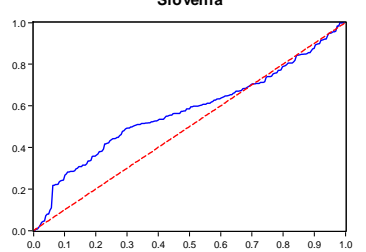

Sweden
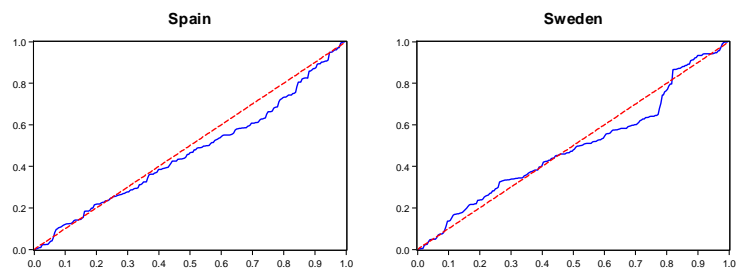

United Arab Emirates
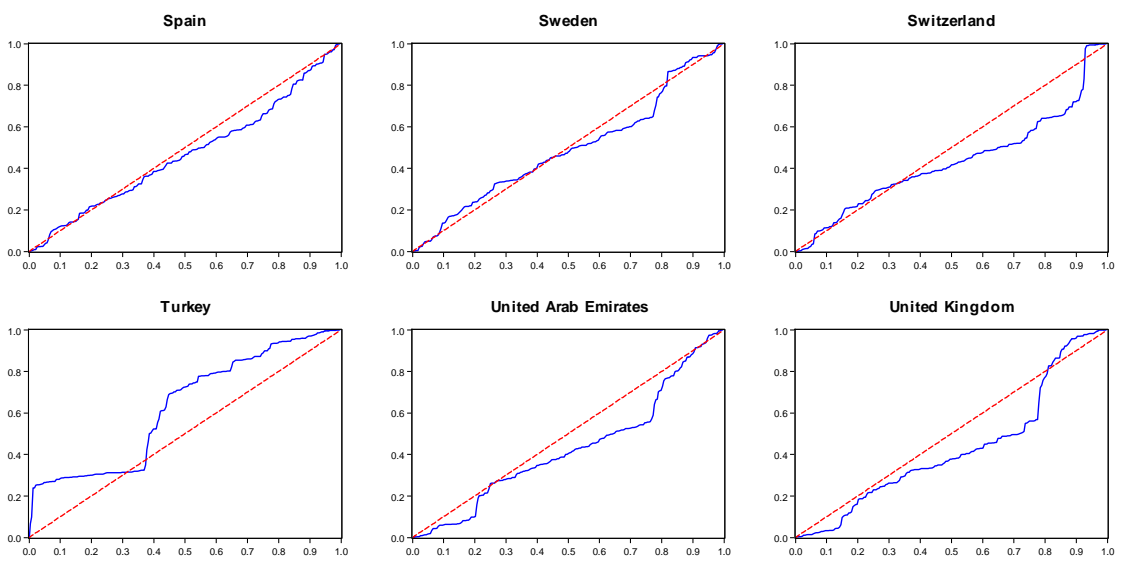

United Kingdom
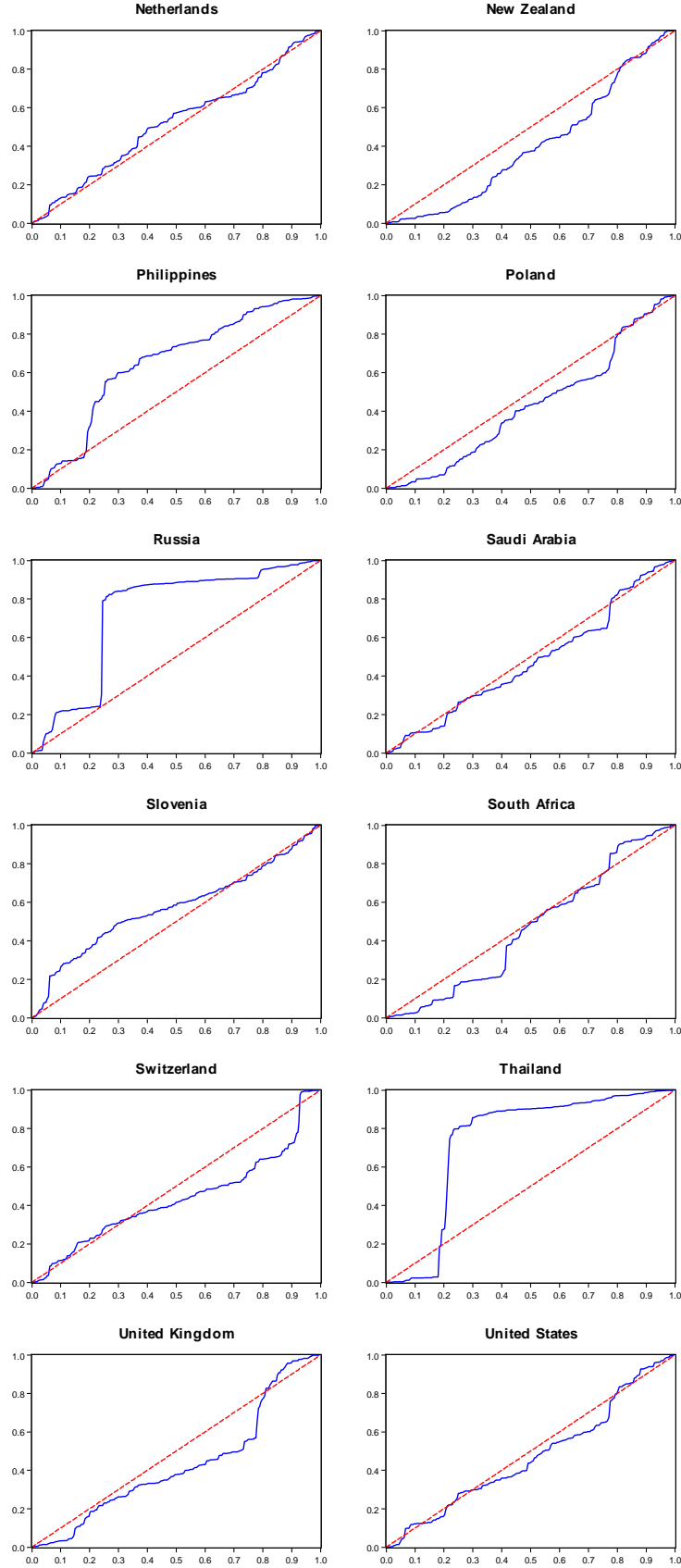

Poland

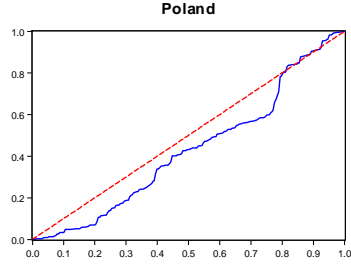

Saudi Arabia

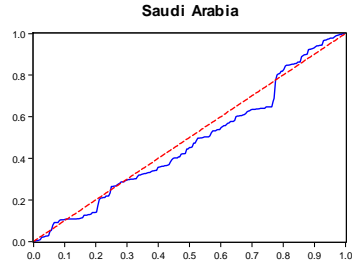

South Africa

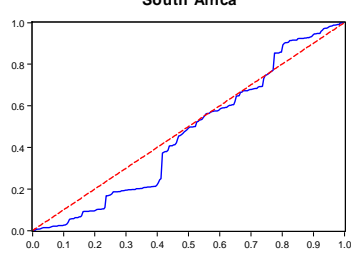

Thailand

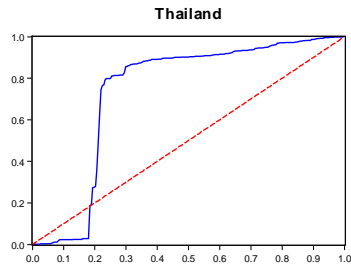

United States
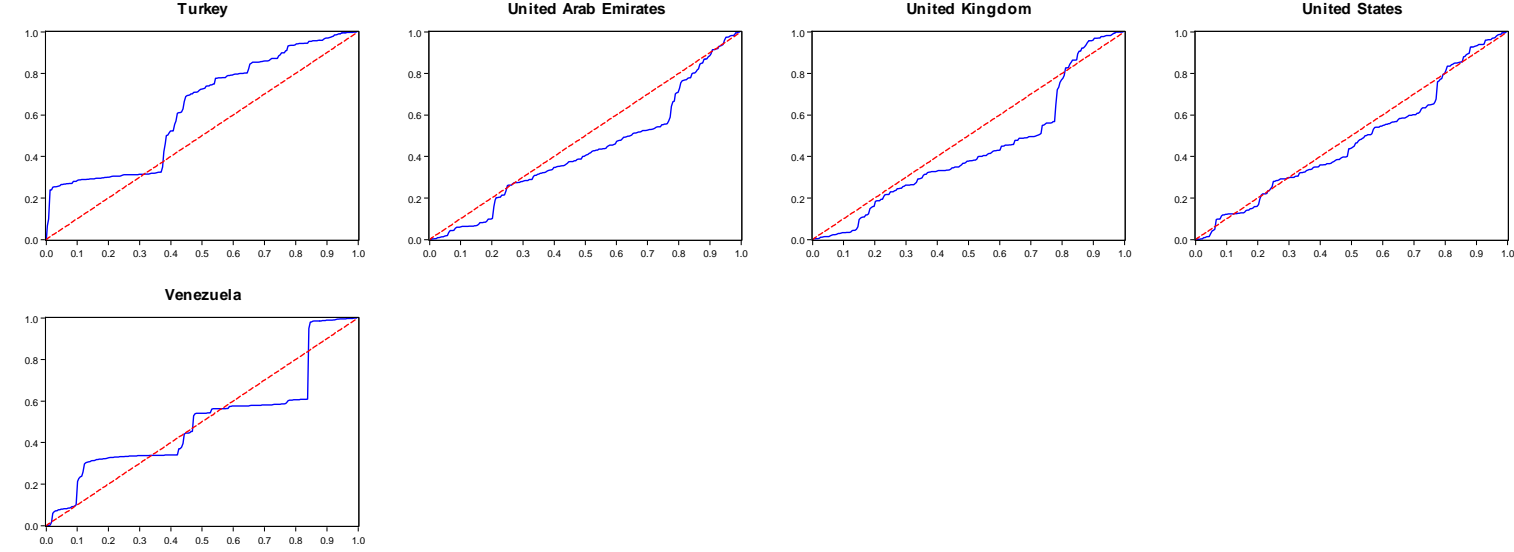